\title{
Unusual Impaction - Rosettes of Multiple Unerupted Molars: Review Article
}

\author{
Nikolay Yanev ${ }^{1}$, Bistra Blagova ${ }^{2,}$,, Laura Andreeva ${ }^{3}$ \\ ${ }^{1}$ Maxillofacial Unit - UMAH N. I. Pirogov, Sofia, Bulgaria \\ ${ }^{2}$ Maxillofacial Surgery Devision, Specialized Hospital for Active Treatment in Dental and Maxillofacial Surgery Medicron, Sofia, Bulgaria \\ ${ }^{3}$ Orthodontic Department, Dental Medicine Faculty, Medical University of Sofia, Sofia, Bulgaria
}

Email address:

n yanev@abv.bg (N. Yanev),dr_blagova@abv.bg (B. Blagova), laura gurgurieva@gmail.com (L. Andreeva)

${ }^{*}$ Corresponding author

\section{To cite this article:}

Nikolay Yanev, Bistra Blagova, Laura Andreeva. Unusual Impaction - Rosettes of Multiple Unerupted Molars: Review Article. International Journal of Dental Medicine. Special Issue: Dento-alveolar Disorders. Vol. 6, No. 1, 2020, pp. 1-6. doi: 10.11648/j.ijdm.20200601.11

Received: November 24, 2019; Accepted: December 9, 2019; Published: July 6, 2020

\begin{abstract}
Background: There is a wide spectrum of syndromes that include dental, oral and craniofacial disorders. Early diagnosis is often crucial for their effective treatment. However, not all syndromes can be clinically identified on time, especially in cases of absence of known family history. Moreover, the treatment of these patients is often complicated because of insufficient medical knowledge and because of the dento-alveolar and craniofacial developmental variations. Objective: The cases of a single impacted tooth are common. But the ones of multiple unerupted permanent molars are a rare phenomenon. They could be either isolated or associated with local or general pathologic factors. When identified, they present a challenging problem for the dentist, or the oral and maxillofacial surgeon. The aim of the article is to review the possible etiology and management modalities in cases of multiple unerupted molars. Results: The Pubmed and Medline database was searched. The information found was presented mainly by case reports. Unfortunately, because of the rarity of this clinical finding and the great clinical diversity, it is difficult to propose clinical procedure protocols. So, we assume, that the real incidence of that condition might be higher than the one mentioned in the literature. Discussion: It seems that due to the rare occurrence of severe complaints, many patients with multiple unerupted molars do not regularly present to their dentists, until other conditions take place. Clinical phenotyping together with reviewed data and evidence-based conclusions will ultimately pave the way for preventive strategies and therapeutic options in the future. This will improve the prognosis for better functional and aesthetic outcome for these patients and lead to a better quality of life. Conclusion: Care of individuals with syndromes affecting craniofacial and dento-alveolar structures is mostly treated by an interdisciplinary team who becomes more frequently involved in the refined diagnostic and etiological processes of these patients. The dentist and the surgical specialist must have a thorough knowledge about the various forms and possible etiology of tooth non-eruption. It can be a sign of various medical conditions. Therefore, detailed and specific investigations are further required, preceding a patient-tailored treatment plan.
\end{abstract}

Keywords: Impacted Teeth, "Kissing” Molars, “Rosettes” of Molars, Unusual Impaction

\section{Introduction}

\subsection{Tooth Eruption and Non-eruption}

Tooth eruption is a multifactorial process of maturation, whose biological mechanism is still unclear. Among the various hypotheses that have been proposed, are the ones of root growth and periodontal formation, the dental follicle theory and the guidance theory $[1,2]$.
The eruption of some teeth may be delayed, and in almost $20 \%$ of the population it does not occur at all. [3, 4] Most commonly it involves the mandibular and maxillary third molars (Figure 1), the maxillary canines (Figure 2) or central incisors/mesiodens (Figure 3) and the mandibular second premolars (Figure 4). [5, 6] The non-eruption of the first and second permanent molars is rarer: $0.03 \%-2.3 \%$. (Figures 4 and 5) [5, 7-9] The prevalence in the normal population is $0.01 \%$ in the case of the first permanent molar, and $0.06 \%$ in 
the case of the second one [5].

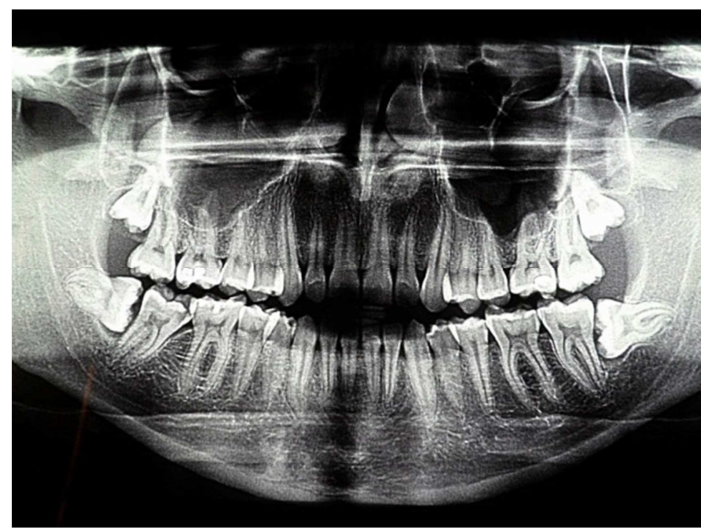

Figure 1. Case \# 1 - a conventional X-ray. Non-eruption of mandibular and maxillary third molars due to an abnormal tooth direction. An example for impaction (teeth \# 38 and \# 48) and primary retention (teeth \# 18 and \# 28).

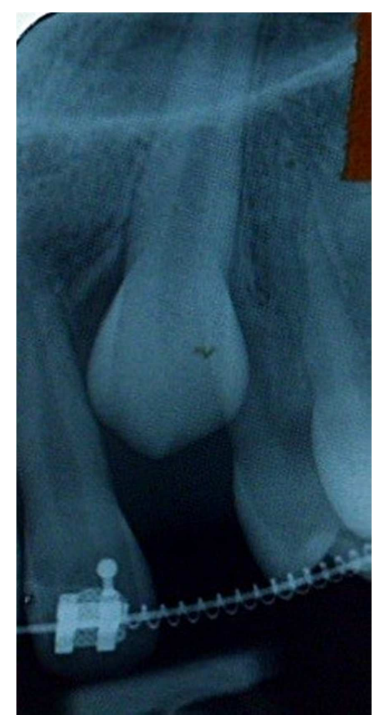

Figure 2. Case \# 2 - a conventional X-ray. Non-eruption of a maxillary canine due to lack of space. An example for impaction.

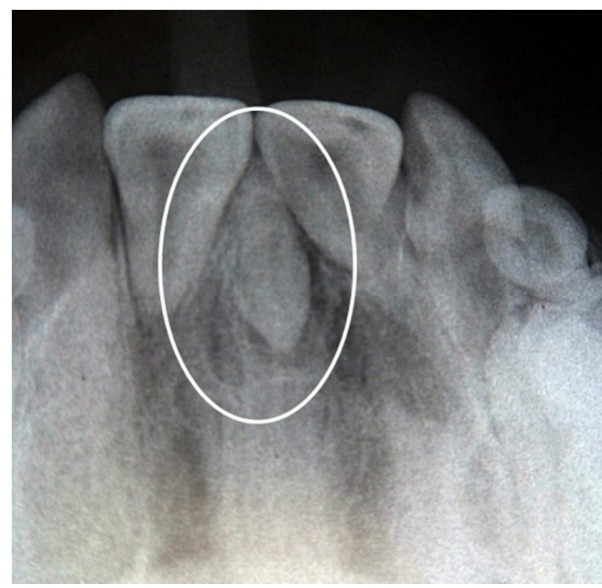

Figure 3. Case \# 3 - a conventional X-ray. Non-eruption of a supernumerary dismorphological tooth - mesiodens. An example for impaction.

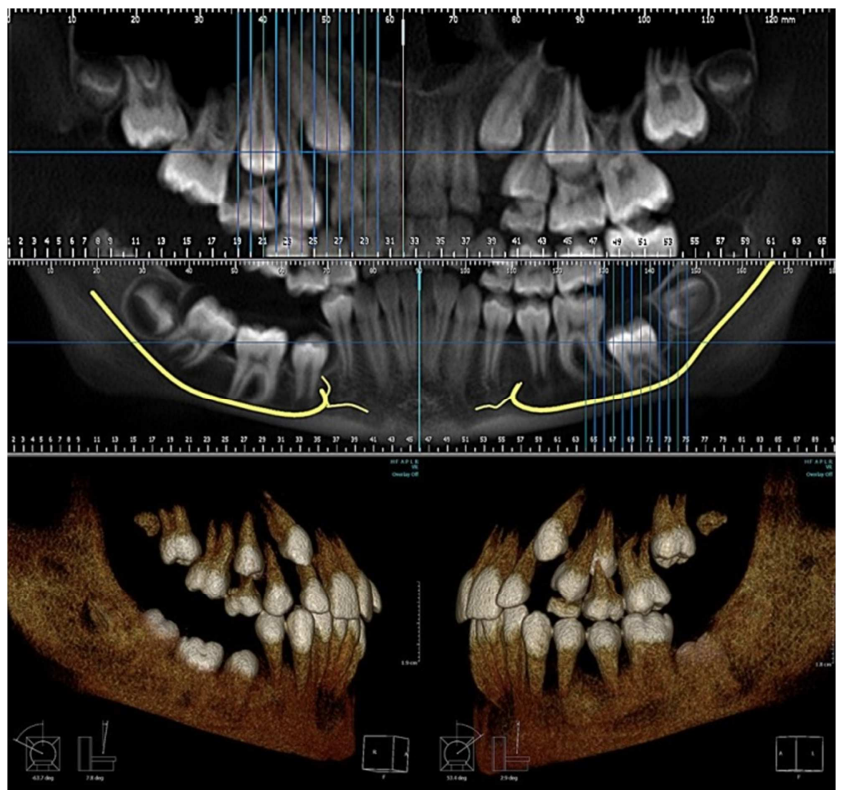

Figure 4. Case \# 4 - a CBCT (cone-beam computed tomography). Noneruption of a mandibular second premolar. An example for primary retention and minimal kissing lower molars.

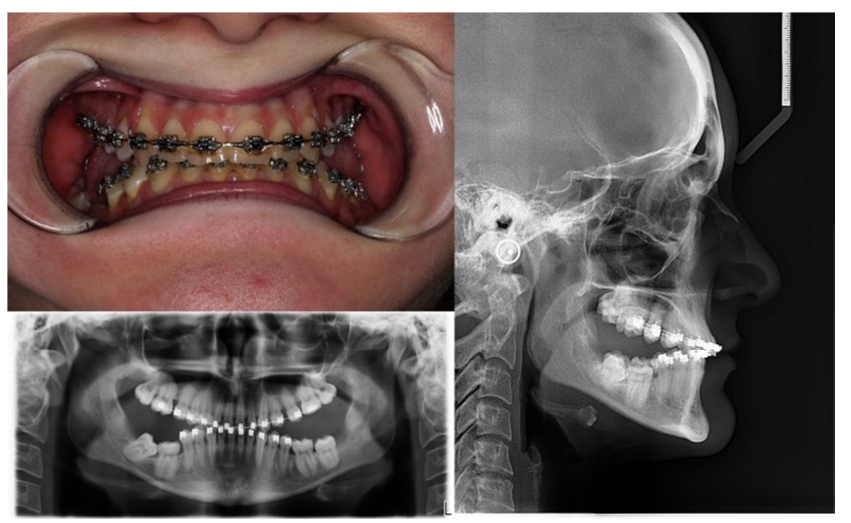

Figure 5. Case \# 5 - conventional X-rays. Non-eruption of the first and second permanent molars. An example for secondary retention - partial kissing. An example for class I non-eruption of first and second molars applied for upper jaw.

\subsection{Classification}

According to the classification by Andreasen and Kurol [10], the absence of eruption of the second molar could be caused by three events: impaction, primary retention and secondary retention [11].

Impaction is the cessation of the eruption of a tooth caused by a clinically or radiographically detectable physical barrier (Figure 3), an abnormal tooth direction (Figure 1 - lower jaw, and Figure 5) or lack of space (Figure 2). Primary retention (unerupted and embedded teeth) refers to the cessation of eruption before emergence, without a physical barrier in the eruption path and not due to an abnormal position. (Figure 1 - upper jaw, and Figure 4) [2] It is probably caused by a disturbance in the dental follicle which fails to initiate the metabolic events responsible for bone resorption in the eruption path. [12] The radiographies show normal orientation of the molar. (Figure 1 - upper jaw, and 
Figure 4) Secondary retention (submerged, re-impaction, ankylosis) refers to the cessation of eruption of a tooth after emergence without a physical barrier in the eruption path and not due to an abnormal position. The infraocclusion is the most reliable clinical finding (Figure 5) [2, 13].

\section{Unusual Non-eruption - "Kissing Phenomenon"}

\subsection{Definition}
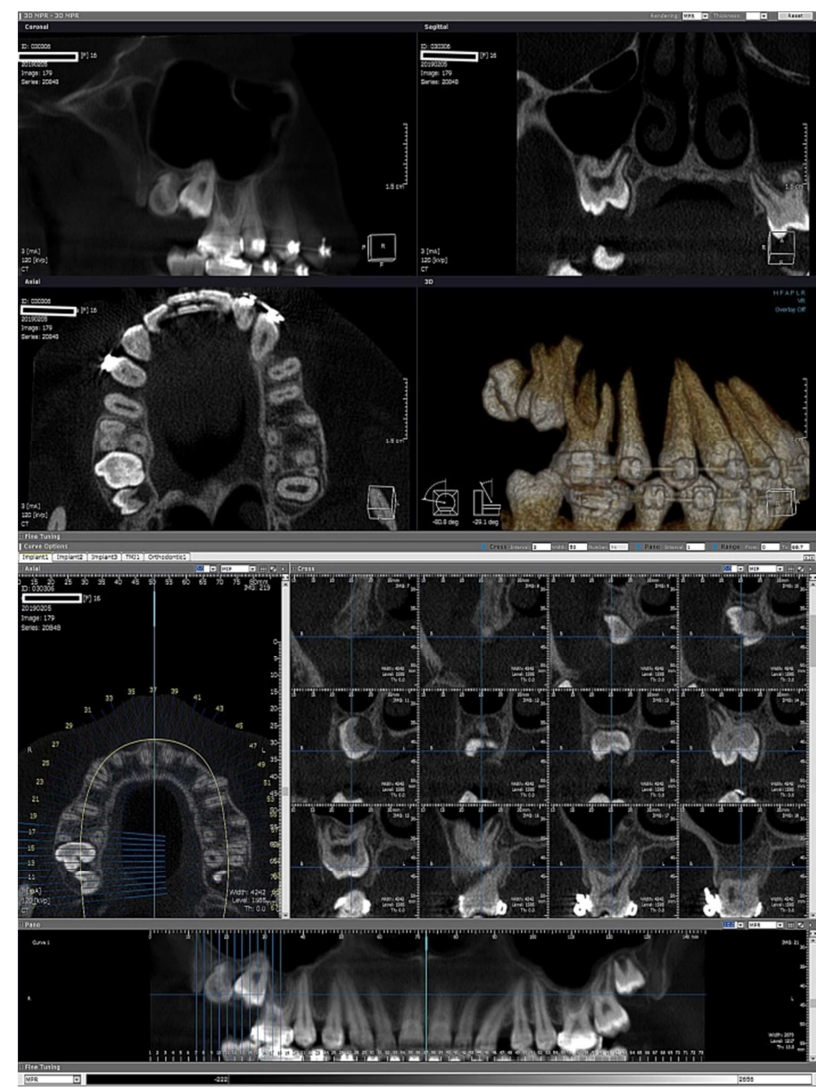

Figure 6. Case \# 6 - a CBCT (cone-beam computed tomography). A 16 year-old female patient with multiple non-erupted permanent molars. An example for class II non-eruption of second and third molars applied for upper jaw.

A special case of multiple unerupted permanent molars are the "kissing" or "rosetting" molars. Van Hoof was the first who described "rosetting" molars in an intellectually retarded 31-year-old man in 1973. [14] Almost 18 years later, in 1991, Robinson et al. [15] proposed the term "kissing" molars to describe a similar condition in a 25 -year-old man. The same year, Nakamura et al. [16] suggested the possible association of "kissing"/"rosetting" molars with MPS (mucopolysaccharidosis) following his radiographic study of three adult cases of MPS. They concluded that "rosetting" molars can occur also as an isolated event. But the possibility of any systemic disease is only suggestive in such cases. [16] Nakamura's associative finding was further corroborated by McIntyre. [17] By definition, "kissing" molars are "impacted mandibular permanent molars that have occlusal surfaces contacting each other while their roots are pointed in the opposite direction, sharing a single follicular space with a continuous cement-enamel junction". [14, 15, 18] However, the term "kissing phenomenon" has also been used to describe a similar appearance with other impacted teeth. [15, 19-21] In the literature, there are controversies regarding the distinction between unusual impaction and rosettes of molars. (Figures $4-8$ ) It has been suggested that the absence of a contact between the two impacted molars discounts them from being classified as "kissing"/"rosetting" [18, 22].

\subsection{Classification}

A classification according to the angle of contact between the two teeth involved in kissing is made to help describe any kissing teeth and to give an impression about the severity of the condition: full kissing (if both teeth facing each other are along the same long axis), partial kissing (there is an obtuse angle between the long axis of crowns of both the teeth Figure 5) and minimal kissing (if the long axis of both the crowns is at an acute angle to each other - Figure 4) [21].

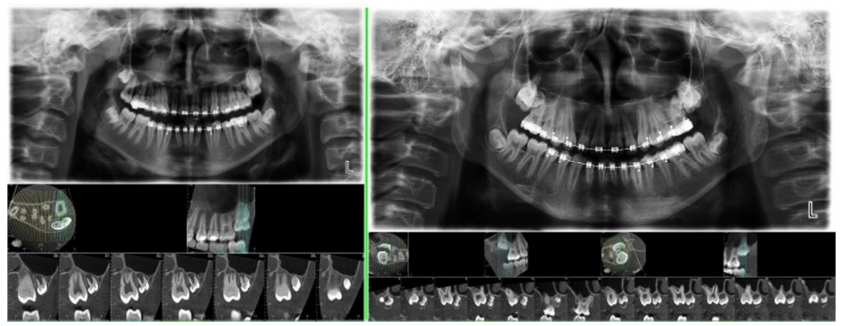

Figure 7. Cases \# $7 \& 8-C B C T$ 's (cone-beam computed tomography). Twins - a female (a) and a male (b). The girl was born with an incomplete cleft palate and underwent an operative correction as a baby. At present in both the non-eruption of the teeth is managed by orthodontic up-righting devices. An example for class II non-eruption of second and third molars applied for upper jaw.

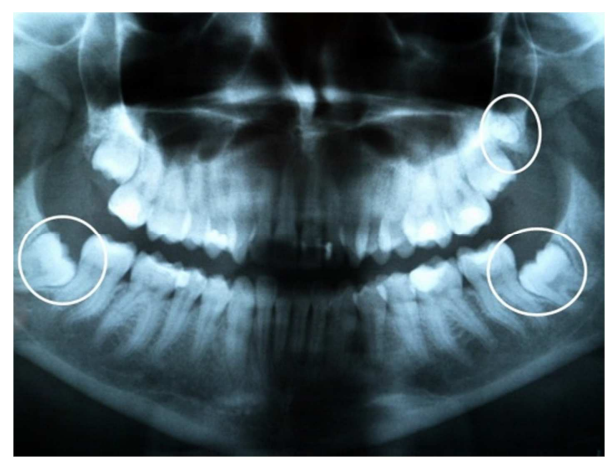

Figure 8. Case \# $9-a$ conventional X-ray. A supernumerary dismorphological tooth \# 29. An example for class III non-eruption of third and fourth molars applied for the upper jaw.

The "kissing"/"rosetting" mandibular molars can be evaluated according to their position. They are classified into three types: class I (impaction of lower first and second molars - Figure 5 - applied for upper ones); class II (impaction of lower second and third molars- Figures 6 and 7 - applied for upper ones); class III (impaction of lower third and fourth molars - Figure 8 - applied for upper ones) [23]. 


\section{Unusual Non-eruption - Etiology and Co-morbidity}

Multiple unerupted "rosetting" molars may occur either as a disease component or an isolated feature. This condition can be caused by systemic or local etiologic factors. It may be also related to syndromes and metabolic disorders.

Among the local factors involved in the failure of eruption are the inclination (Figures 1,4-6) and the depth of the molar (Figures 4 and 6), the developmental stage of the root (Figures 4, 6 and 7), malocclusion disturbances of the deciduous dentition, the position of the adjacent teeth (Figures 2 - 4), space deficiency in the dental arch, supernumerary teeth (Figures 3 and 8), odontomas or cysts. $[6,7,24]$ According to a study by Baykul et al. [25], 50\% of the total cases investigated by them were associated with dentigerous cyst. Moreover, patients with unerupted molars have been reported to have a more frequent occurrence of dismorphological teeth (Figures 3 and 8) and cranial anomalies (Figure 7) [9, 26].

Authors like Sun et al. [27], Sandler et al. [28] and Cho et al. [29] reported that HDF (hyperplastic dental follicles, or its synonym peri-follicle fibrosis), CHDF (calcified hyperplastic dental follicles) and premature calcifications, which are different to HDF, can involve multiple unerupted/impacted teeth. These conditions are extremely rare, with exclusive male predilection. [24] On the other hand, several studies have revealed no gender differences in tooth non-eruption [7, 26].

However, heredity is also mentioned as an etiologic factor and a more recent report suggested a genetic tendency as a possible cause. [27] Hata et al. [30] reported dentofacial manifestations of $X X X X Y$ syndrome involving molars noneruption. Recently, mutations in PTH1R (parathyroid hormone receptor 1 ) have been identified in several familial cases of primary failure of eruption. [31, 32] In a current study, Shapira et al. [33] investigated genetic traits in molar non-eruption and found that the Chinese - American population had a higher prevalence $(2.3 \%)$ compared with the Israeli population (1.4\%).

Disturbanses in teeth development can be linked with conditions such as mucopolysaccharidoses [16, 34], cleidocranial dysostosis [35, 36], Gardner syndrome [37] and Yunis-Varon syndrome [38]. Other conditions which can be considered in the differential diagnosis in multiple unerupted teeth are NBCCS (nevoid basal cell carcinoma syndrome) or Gorlin syndrome/ Gorlin-Sedano syndrome [39, 40], familial fibrous dysplasia or cherubism. Therefore, in each case with abnormal dental eruption feature, further work-up should be performed, in order to rule out any systemic disorders or syndromes.

\section{Management Strategies}

The decision about removal of "rosetting" molars is a surgical challenge for the oral/maxillofacial surgeon. [41] This can be explained by the elevated rates of complications
(4.6\% to $30.9 \%$ ) that can be assigned to the removal of impacted teeth [42], such as mandibular fractures during the surgery $[43,44]$ or post-operation [41, 43-45], dry socket $[43,44]$ or damage to the alveolar nerve [46-48]. On the other hand, the maintenance of these teeth can be connected to other complications, such as reduction of mandible bone tissue, which on its behalf increases the risk of mandibular fractures [46, 49], root resorption of adjacent teeth, pericoronaritis, local pain or cystic changes [50]. In order to reduce or prevent these complications, it is mandatory to have a detailed surgical planning, as well as awareness of both the professionals and patients about the nature of the condition. [51] At the moment of surgical planning, the panoramic X-rays often combined with a cone beam computed tomography $(C B C T)$ are considered base-line of the diagnostic process (Figures 4-7) [48].

There is no standard solution in treating of multiple unerupted molars. Different approaches are proposed and should be taken into consideration in each individual case. Extraction of both "kissing"/"rosetting" molars or only the one of them with/without exposure of the non-extracted tooth are yet the most successful surgical protocol reported in the literature. $[8,52]$ The orthodontic up-righting by different mechanics and devices such as push spring and mini-hook systems are also well applied as an alternative conservative approach. (Figures 5 and 7) [53, 54] However, the management plan depends on several local factors, such as: tooth inclination and position, as well as the degree of teeth crowding or follicle collision. These influence not only the treatment but also the prognosis and outcome. The ideal procedure should allow the establishment of a normal functional occlusal relationship.

\section{Meaning of Non-eruption}

The eruption of the first and second permanent molars is especially important for the co-ordination of the facial growth and for providing sufficient occlusal support for undisturbed mastication. [1] Early diagnosis and early treatment are the keys for successful correction of molar non-eruption. Therefore, a radiographic examination (ideally during the early mixed dentition period) is recommended. The proper time to treat these types of disorders is between 11 and 14 years while second molar root formation is still incomplete and before the third molars complete their development in close proximity to the second ones. [6, 33] Close collaboration between the specialists (surgeons, orthodontists, pediatric dentists, etc.) is mandatory for the successful outcome. Management of such cases is considered very difficult, unpredictable and challenging. It also often requires a complex surgery, which is dependent on experience and great attention to details from the surgeon $[17,20]$.

Unfortunately, because of the rarity of this clinical finding and the great clinical diversity, it is difficult to propose clinical procedure protocols. Many factors such as age, occlusion, the presence of the adjacent molars, the degree of crowding, pathological conditions, the teeth position and their root 
anatomy, as well as patient cooperation and expectations should be considered, before formulating the final treatment decision and plan. $[6,8,26,33,55]$ Most importantly, the potential risks and complications and the possible benefits of other treatment modalities should be brought to the patient's mind and thoroughly explained, before proceeding with an intervention, on each individual case basis.

\section{Conclusion}

In conclusion, the dentist and the surgical specialist, must have a thorough knowledge about the various forms and possible etiology of tooth non-eruption. It can be a sign of various medical conditions. Therefore, detailed and specific investigations are further required, preceding a patienttailored treatment plan.

\section{References}

[1] Palma C., Coelho A., Yndira González Y., Cahuana A. 2003. Failure of eruption of first and second permanent molars. $J$ Clin Pediatric Dent, 27 (3): 239-45.

[2] Raghoebar G. M, Boering G., Vissink A, Stegenga B. 1991. Eruption disturbances of permanent molar: a review. $J$ Oral Pathol Med, 20: 159-66.

[3] Andreasen J. O., Petersen J. K., Laskin D. M. 1997. Textbook and color atlas of tooth impactions. Copenhagen, Denmark. Munksgaard; pp. 199-208.

[4] Kaban L. B., Needleman H. L., Hertzberg J. 1976. Idiopathic failure of eruption of permanent molar teeth. Oral Surg, 42: $155-63$.

[5] Grover P. S. \& Norton L. 1985. The incidence of unerupted permanent teeth and related clinical cases. Oral Surg Oral Med Oral Path, 420-5.

[6] Sawicka M., Racka-Pilszak B., Rosnowska-Mazurkiewicz A. 2007. Uprighting partially impacted permanent second molars. Angle Orthod, 77: 148-54.

[7] Bondemark L. \& Tsiopa J. 2007. Prevalence of ectopic eruption, impaction, retention and agenesis of the permanent second molar. Angle Orthod, 77 (5): 773-8.

[8] Magnusson C. \& Kjellberg H. 2009. Impaction and retention of second molars: diagnosis, treatment and outcome. A retrospective follow-up study. Angle Orthod, 79 (3): 422-7.

[9] Vedtofte H., Andreasen J. O., Kjaer I. 1999. Arrested eruption of the permanent lower second molar. Eur J Orthod, 21: 3140 .

[10] Andreasen J. \& Kurol J. 1977. The impacted first and second molar. Andreasen J. O. \& Petersen J. K. L. D., eds In: Textbook and color atlas of tooth impactions Copenhage. Munksgaard, pp. 197-218.

[11] Boffano P., Gallesio C., Bianchi F., Roccia F. 2010. Surgical extraction of deeply horizontally impacted mandibular second and third molars. J Craniofac Surg, 21 (2): 403-6.

[12] Oliver R. G., Richmond S., Hunter B. 1986. Submerged permanent molars: four case reports. Br Dent $J, 160$ : 128-30.
[13] Raghoebar G. M., Boering G., Jansen H. W. B., Vissink A. 1989. Secondary retention of permanent molar: a histologic study. J Oral Pathol Med, 18: 427-31.

[14] Van Hoof R. F. 1973. Four kissing molars. Oral Surg Oral Med Oral Pathol, 35: 284.

[15] Robinson A. J., Gaffrey W. Jr., Soni N. N. 1991. Bilateral kissing molars. Oral Surg Oral Med Oral Pathol, 72: 760.

[16] Nakamura T., Miwa K., Kanda S., Nonaka K., Anan H., Higash S., Beppu K. 1992. Rosette formation of impacted molar teeth in mucopolysaccharidoses and related disorders. Dentomaxillofac Radiol, 21: 45-9.

[17] McIntyre G. 1997. Kissing molars: an unexpected finding. Dent Update, 24 (9): 373-4.

[18] Juneja M. 2008. Not kissing. Br Dent J, 204: 597.

[19] Ashok D., Pradeep A., Ram Rashad Y., Arun Kumar M., Anjani Kumar Y., Ashish S., Mehul Rajesh J. 2017. Kissing canines associated with dentigerous cyst, a case report of transmigrated bilateral impacted mandibular canines. Int $J$ Oral Craniofac Sci, (1): 014-6.

[20] Bakaeen G. \& Baqain Z. H. 2005. Interesting case: Kissing molars. Br J Oral Maxillofac Surg, 43: 534.

[21] Jomhawi J. M., Odat A. M., Sethuraman R., Al-Nabulsi M. H. 2018. Kissing premolars and follow up of the eruption of the impacted premolar over 3 years: a rare case report. $J$ Dent Health Oral Disord Ther, 9 (2): 00329.

[22] Krishnan B. 2008. Kissing molars. Br Dent J, 204: 281-2.

[23] Shahista P., Mascarenhas R., Shetty S., Husain A. 2013. Kissing molars: an unusual unexpected impaction. Archiv Med Health Sci, 1: 52-3.

[24] Varpio M. \& Wellfelt B. 1988. Disturbed eruption of the lower second molar: clinical appearance, prevalence, and etiology. ASDC J Dent Child, 55: 114-8.

[25] Baykul T., Saglam A. A., Aydin U., Basak K. 2005. Incidence of cystic changes in radiographically normal impacted lower third molar follicles. Oral Surg Oral Med Oral Pathol Oral Radiol Endod, 99: 542-5.

[26] Kenrad J., Vedtofte H., Andreasen J. O., Kvetny M. J., Kjær I. 2011. A retrospective overview of treatment choice and outcome in 126 cases with arrested eruption of mandibular second molars. Clin Oral Invest, 15: 81-7.

[27] Sun C. X., Ririe C., Henkin J. M. 2010. Hyperplastic dental follicle: review of literature and report of two cases in one family. Chin J Dent Res, 13: 71-5.

[28] Sandler H. J., Nersasian R. R., Cataldo E., Pochebit S., Gayal Y. 1988. Multiple dental follicles with odontogenic fibromalike changes (WHO-type). Oral Surg Oral Med Oral Pathol, 66: $78-84$.

[29] Cho Y. A., Yoon H. J., Hong S. P., Lee J. I., Hong S. D. 2011. Multiple calcifying hyperplastic dental follicles: comparison with hyperplastic dental follicles. J Oral Pathol Med, 40: 2439.

[30] Hata S., Maruyama Y., Fujita Y., Mayangi H. 2001. The dentofacial manifestations of XXXXYsyndrome: a case report. Int J Paediat Dent, 11: 138-42. 
[31] Frazier-Bowers S. A., Simmons D., Koehler K., Zhou J. 2009. Genetic analysis of familial non-syndromic primary failure of eruption. Orthod Craniofac Res, 12: 74-81.

[32] Frazier-Bowers S. A., Simmons D., Wright J. T., Proffit W. R., Ackerman J. L. 2010. Primary failure of eruption and PTH1R: the importance of a genetic diagnosis for orthodontic treatment planning. Am J Orthod Dentofacial Orthop, 137 (160): $1-7$.

[33] Shapira Y., Finkelstein T., Shpack N., Lai Y. H., Kuftinec M. M., Vardimon A. 2011. Mandibular second molar impaction. Part I: genetic traits and characteristics. Am J Orthod Dentofacial Orthop, 140: 32-7.

[34] Cawson R. A. 1962. The oral changes in gargoylism. Proc $R$ Soc Med, 55: 1066-70.

[35] Kirson L. E., Scheiber R. E., Tomaro A. J. 1982. Multiple impacted teeth in cleidocranial dysostosis. Oral Surg Oral Med Oral Pathol, 54: 604

[36] Yýlmaz H. H., Ucok O., Dogan N., Ozen T., Karakurumer K. 2002. Kleidokranial displazi (olgu raporu). CU Dishek Fak Derg, 5: 33-5.

[37] Bradley J. F. \& Orlowski W. A. 1977. Multiple osteomas, impacted teeth and odontomas - a case report of Gardner's syndrome. J N J Dent Assoc, 48: 32-3.

[38] Lapeer G. L. \& Fransman S. L. 1992. Hypodontia, impacted permanent teeth, spinal defects and cardiomegaly in a previously diagnosed case of the Yunis-Varon syndrome. Oral Surg Oral Med Oral Pathol, 73: 456-60.

[39] Gorlin R. J \& Sedano H. O. 1971. Cryptodonticbrachymetacarpalia. In: Birth Defects Original Article Series. New York, 7 (7): 200-3.

[40] Muzio L. O. 2008. Nevoid basal cell carcinoma syndrome (Gorlin syndrome). Orphanet J Rare Diseases, 3: 32.

[41] Almendros-Márques N., Alaejos-Algarra E., QuinterosBorgarello M., Berini-Aytés L., Gay-Escoda C. 2008. Factors influencing the prophylatic removal of asynptomatic impacted lower third molar. Int J Oral Maxillofac Surg, 37: 29-35.

[42] Bouloux G. F., Steed M. B., Perciaccante V. J. 2007. Complications of third molar surgery. Oral Maxillofac Surg Clin North Am, 19: 117-28.

[43] Adeyemo W. L. 2006. Do pathologies associetes with impacted lower third molar justify prophylactic removal? A critical review of the literature. Oral Surg Oral Med Oral Pathol Oral Radiol Endod, 102: 448-52.
[44] Woldenberg Y., Gatot I., Bodner L. 2007. Iatrogenic mandibular fracture associated with third molar removal. Can it be prevented? Med Oral Patol Oral Cir Bucal, 12: 70-2.

[45] Al-Belasy Fa, Tozoglu S., Ertas U. 2009. Mastication and late mandibular fracture after surgery of impacted third molars associated with no gross pathology. J Oral Maxillofac Surg, 67: 856-61.

[46] Lee J. T. \& Dodson T. B. 2000. The effect of mandibular third molar presence and position on the risk of an angle fracture. $J$ Oral Maxillofac Surg, 58: 394-9.

[47] Susarla S. M., Blaeser B. F., Magalnick D. 2003. Third molar surgery and associated complications. Oral Maxillofac Surg Clin North Am, 15: 177-86.

[48] Valmaseda-Castellón E., Berini-Aytés L., Gay-Escoda C. 2001. Inferior alveolar nerve damage after lower third molar surgical extraction: a prospective study of 1117 surgical extractions. Oral Surg Oral Med Oral Pathol Oral Radiol Endod, 92: 377-83.

[49] Iida S., Hassfeld S., Reuther T., Nomura K., Mühling J. 2005. Relationship between the risk of mandibular angle fractures and the status of incompletely erupted mandibular third molars. J Craniomaxillofac Surg, 33: 158-63.

[50] Gbotolorun O. M., Arotiba G. T., Ladeinde A. L. 2007. Assessment of factors associated with surgical difficulty in impacted mandibular third molar extraction. J Oral Maxillofac Surg, 65: 1977-83.

[51] Marciani R. D. 2007. Third molar removal: an overview of indications, imaging, evaluation and assessment of risk. Oral Maxillofac Surg Clin North Am, 19: 1-13.

[52] Arjona-Amo M., Torres-Carranza E., Batista-Cruzado A., Serrera-Figallo MA., Crespo-Torres S., Belmonte-Caro R., Albuso-Andrade C., Torres-Lagares D., Gutierrez-Perez JL. 2016. Kissing molars extraction: case series and review of the literature. J Clin Exp Dent, 8 (1): e97-101.

[53] Reddy S. K., Uloopi K. S., Vinay C., Subba Reddy V. V. 2008. Orthodontic uprighting of impacted mandibular permanent second molar: a case report. J Indian Soc Pedod Prevent Dent, 26 (1): 29-31.

[54] Barros S. E., Janson G., Chiqueto K., Ferreira E., Rösing C. 2018. Expanding torque possibilities: a skeletally anchored torqued cantilever for uprighting "kissing molars". $\mathrm{Am} J$ Orthod Dentofacial Orthop, 153: 588-98.

[55] Kurol J. 2006. Impacted and ankylosed teeth: why, when, and how to intervene. Am J Orthod Dentofacial Orthop, 129: 86-90. 